\title{
RISK FACTORS OF BREAST CANCER IN SOUTH-EAST ASIA: A SYSTEMATIC REVIEW
}

\author{
Hindun Rahim
}

Masters Program in Midwifery, Aisyiyah University Yogyakarta

\begin{abstract}
Background: Breast cancer is a reproductive cancer that increases morbidity and mortality. Global Burden Cancer data showed, breast cancer incidence has increased by more than $20 \%$, while the mortality rate has increased by $14 \%$ since 2008 . This study aimed to systematically review the risk factors of breast cancer in South-East Asia.

Subjects and Method: A systematic review were conducted by searching articles from electronic databases. The keywords were "breast cancer" OR "breast cancer risk" AND "parity" OR "contraceptive" Or "smoking" AND "South-East Asia”. The dependent variable was breast cancer. The independent variables included age, body mass index, menarche, menopause, parity, contraceptive use, breastfeeding, and smoking. The data were reviewed using PRISMA flow diagram.

Results: Seven articles met the inclusion criteria. Articles reported that age, obesity, menarche at an early age, unhealthy lifestyles, menopause, contraceptive use, and $\mathrm{Hu}$ man Papilloma Virus (HPV) infection were associated with the incidence of breast cancer in South-East Asia.

Conclusion: Breast cancer incidence increases with age, obesity, menarche at an early age, unhealthy lifestyles, menopause, contraceptive use, and HPV infection.

\section{Correspondence:}

Hindun Rahim. Masters Program in Midwifery, Universitas Aisyiyah Yogyakarta, Yogyakarta. Indonesia. Email:hindunrahim171090@gmail.com. Mobile: 085256451126.
\end{abstract}

